\title{
青海湖嗜盐微生物篮选分离与生长特性"
}

\author{
沈国平 $^{1}$, 朱德锐 ${ }^{1 * *}$, 刘 建 $^{2}$, 韩 点 $^{3}$, 龙启福 ${ }^{1}$ \\ ( 1 : 青海大学医学院, 西宁 810016$)$ \\ ( 2 : 华中师范大学生命科学学院, 武汉 430079) \\ (3: 青海大学农林科学院, 西宁 810016)
}

摘 要: 为全面获得青海湖嗜盐菌种质资源, 构建种群系统发育树和确定种群进化定位. 采用高盐选择性培养基篮选, 分离从 20 份青海湖水样中获得 35 株青海湖嗜盐微生物. 耐盐梯度实验表明: 水体中以中度嗜盐菌为主, 约占 $62.85 \%$, 轻 度嗜盐菌约占 $22.85 \%$, 非嗜盐菌与耐盐菌约占 $14.28 \%$. 青海湖中度嗜盐微生物能在 $10 \sim 45^{\circ} \mathrm{C}, \mathrm{pH} 5.5 \sim 11.0$ 的范围内 生长, 与地区盐碱化环境相关, 具有嗜盐兼嗜碱微生物的特性.

关键词: 青海湖; 嗜盐菌; 分离篮选; 生长特性

\section{Isolation and characteristics of halophile microorganisms from Lake Qinghai}

\author{
SHEN Guoping ${ }^{1}$, ZHU Derui $^{1}$, LIU Jian ${ }^{2}$, HAN Rui ${ }^{3} \&$ LONG Qifu ${ }^{1}$ \\ (1: Medical Cuollege, Qinghai University, Xining 810016, P. R. China) \\ (2: College of Life Science, Huazhong Normal University, Wuhan 430079, P. R. China) \\ (3: Provincial Agricultural Academy of Science, Qinghai University, Xining 810016, P. R. China)
}

\begin{abstract}
The main objective of the project is to obtain completely halophile germplasm resources from Lake Qinghai, to construct stocks phyletic evolution tree of halophilic bacterium and determine the evolution position. 35 strains were isolated from 20 water samples taken from Lake Qinghai using the high salty medium. Resistant to salt gradient experiment shows that moderate halophilic bacteria account for about $62.85 \%$ in the water, mild halophilic bacteria account for about $22.85 \%$, non halophilic bacteria and salt resistance bacteria account for $14.28 \%$. Moderate halophilic bacteria could grow in the temperature of $10 \sim 45^{\circ} \mathrm{C}$ and $\mathrm{pH} 5.5 \sim$ 11.0 , which is related to the local salinization environment and has characteristic of hasophilic microorganisms.
\end{abstract}

Keywords: Lake Qinghai; halophile microorganisms; isolation; characteristics

青海湖 $\left(36^{\circ} 32^{\prime} \sim 38^{\circ} 15^{\prime} \mathrm{N}, 99^{\circ} 36^{\prime} \sim 100^{\circ} 47^{\prime} \mathrm{E}\right)$ 位于青藏高原东北隅 ${ }^{[1]}$, 是中国最大的内陆湖泊, 也是中 国最大的咸水湖, 地处西北干旱/半干旱环境敏感带 ${ }^{[2]}$, 具有重要的生态环境研究价值. 青海湖是青藏高原 生物多样性最丰富的宝库, 也是极端微生物基因资源的宝库, 其海拔 $3195 \mathrm{~m}$, 水温低, 盐度略低于海水, 水体 中富集嗜盐微生物. 嗜盐微生物作为一类新型的、极具应用前景的海洋微生物资源, 近年倍受关注, 诸如嗜 盐机理、细菌视紫红质和嗜盐菌素等基础研究, 环境生物治理、生物电子和医药工业等应用研究方面 ${ }^{[3]}$.

目前, 根据海洋原核生物名录统计共 846 属 2292 种, 其中海洋古菌 66 属 189 种, 海洋细菌 780 属 2103 种 ${ }^{[4]}$. 随着海洋、湖泊微生物的多样性、生态、生理、生化、遗传和进化研究, 必将丰富基因组学及后基因组 学, 亦将推动海洋、湖泊微生物资源的开发与应用研究. 嗜盐微生物作为重要的海洋和咸水湖泊微生物类群 之一, 主要包括嗜盐古菌、嗜盐细菌和嗜盐真核微生物三类, 其中嗜盐古菌科 (Halobacteria) 现有 18 属 $^{[5]}$. 近 年来, 我国学者针对西藏、新疆、内蒙古等西部地区盐湖 ${ }^{[6]}$ 、南极深海 ${ }^{[7]}$ 、青岛盐田 ${ }^{[8]}$ 、舟山地区 ${ }^{[9]}$ 的报道相 对较多, 而对青海湖嗜盐微生物的研究相对较少. 鉴于青海湖生态环境条件特殊, 属内陆盐湖, 缺氧低压, 昼

* 国家自然科学基金项目(31060013)资助. 2011-03-18 收稿;2011-08-02 收修改稿. 沈国平,女, 1976 年生,副教 授;E-mail:sgpkkll@126.com.

** 通信作者;E-mail : zhuderui2005@126. com. 
夜温差大, 其微生物具有典型的生理生化适应性. 本研究旨在分离筛选青海湖优势嗜盐菌以获得全面的种 质资源, 以此了解青海湖嗜盐微生物的多样性, 为后续构建种群系统发育树, 确定种群进化定位和嗜盐微生 物资源的开发利用提供基础.

\section{1 材料与方法}

\section{1 样品来源}

2009 年 7 月,沿环湖路线采集青海湖渔场、湖东洱海旅游景区、青海湖宾馆、青海湖二郎剑景区、黑马 河、塘曲、冬格日陇哇、鸟岛、海心山等地区水样 20 份, 样品采集后置于 $4{ }^{\circ} \mathrm{C}$ 冰箱暗处保存.

\section{2 主要试剂}

Yeast extract(英国 OXOID 公司)、细菌蛋白胨、柠檬酸钠、葡萄糖、 $\mathrm{NaCl} 、 \mathrm{KCl} 、 \mathrm{MgSO}_{4} \cdot 7 \mathrm{H}_{2} \mathrm{O} 、 \mathrm{CaCl}_{2} \cdot 2 \mathrm{H}_{2} \mathrm{O}$ 和琼脂粉等(分析纯, 天津恒兴公司).

\section{3 主要仪器}

电热恒温干燥箱 (PH050, 上海实验仪器厂) 、电子天平 (PL203 METTLER TOLEDO 公司)、恒温摇床 (ZD85 , 上海精达公司)、恒温培养箱 (ZHWY-100B, 上海智城公司)、无菌操作台 (上海博讯公司)、754 紫外分光 光度计 (上海光谱仪器).

\section{4 菌株分离和形态特征观察}

菌种分离和富集培养采用 $\mathrm{RM}$ 培养基 ${ }^{[10]}: 1 \mathrm{~L}$ 培养基含 $\mathrm{NaCl} 50.0 \mathrm{~g}$, 无水 $\mathrm{MgSO}_{4} 9.7 \mathrm{~g}$, 柠檬酸钠 $3.0 \mathrm{~g}$, $\mathrm{KCl} 2.0 \mathrm{~g}$, 无水 $\mathrm{CaCl}_{2} 0.2 \mathrm{~g}$, 细菌蛋白胨 $10.0 \mathrm{~g}$, 酵母抽提物 $2.0 \mathrm{~g}, \mathrm{pH}$ 7. 5. 固体培养基加琼脂 $15 \mathrm{~g}, 121^{\circ} \mathrm{C}$ 灭 菌 $15 \mathrm{~min}$, 保存备用.

将采集的水样直接加到液体培养基中 $(1: 100), 37^{\circ} \mathrm{C} 、 120 \mathrm{r} / \mathrm{min}$, 恒温振荡培养 $3 \mathrm{~d}$. 取培养基 $10 \mu \mathrm{l}$, 稀 释 $(\times 1000)$ 后涂布平板, $37^{\circ} \mathrm{C}$ 恒温培养, 依据菌落形态 (形状、大小、颜色及表面特征), 挑取单菌落反复划线 纯化3 4 次, 将最后一次挑取的单菌落接人液体培养基, 振荡培养 $12 \mathrm{~h}, 10 \%$ 甘油, $-20^{\circ} \mathrm{C}$ 冻存备用. 在 RM 固体培养基上观察菌落形态, 采用革兰氏染色法在光镜下观察菌体形态.

\section{5 生长特性研究}

耐盐度试验 ${ }^{[11]}$ : 过夜培养菌株, 以 $1 \%$ 接种量接种于不同 $\mathrm{NaCl}$ 浓度梯度的 $\mathrm{RM}$ 液体培养基中 $(\%, \mathrm{~W} / \mathrm{V}$ : $0 、 0.25 、 0.50 、 0.75 、 1.00 、 1.25 、 1.50 、 1.75 、 2.00 \sim 17.50)$, 三组平行, $37^{\circ} \mathrm{C} 、 150 \mathrm{r} / \mathrm{min}$ 振荡培养 $12 \mathrm{~h}$, 用 722 分光光度计测定培养液光密度值 $\left(O D_{600}\right)$, 取其平均值.

最适生长温度试验 ${ }^{[11]}$ : 将菌株接种于含 $5 \% \mathrm{NaCl}$ 的 $\mathrm{RM}$ 液体培养基中, 分别置于 $10 、 15 、 20 、 25 、 30 、 35$ 、 $37 、 40 、 45^{\circ} \mathrm{C}$ 温度梯度中, 三组平行, $150 \mathrm{r} / \mathrm{min}$ 振荡培养 $12 \mathrm{~h}$, 测定培养液的光密度值 $\left(O D_{600}\right)$, 取其平均值.

$\mathrm{pH}$ 值对生长影响的测定 ${ }^{[11]}$ : 将菌株接种于 $\mathrm{pH} 3 \sim 12$ 的含 $5 \% \mathrm{NaCl}$ 浓度的 $\mathrm{RM}$ 液体培养基中,三组平 行, $37^{\circ} \mathrm{C} 、 150 \mathrm{r} / \mathrm{min}$, 振荡培养 $12 \mathrm{~h}$, 测定培养液的光密度值 $\left(O D_{600}\right)$, 取其平均值.

$\mathrm{Mg}^{2+}$ 对生长影响的测定:将菌株接种于 $0 \sim 2.0 \mathrm{~mol} / \mathrm{L}$ 的 $\mathrm{MgSO}_{4}$ 的 $\mathrm{RM}$ 液体培养基中, 三组平行, $37^{\circ} \mathrm{C}$ 、 $150 \mathrm{r} / \mathrm{min}$ 振荡培养 $12 \mathrm{~h}$,测定培养液的光密度值 $\left(O D_{600}\right)$, 取其平均值.

\section{6 碳氮源利用实验}

碳氮源利用实验, 参照《常见细菌系统鉴定手册》 ${ }^{[12]}$ 和《伯杰氏细菌鉴定手册》(第 8 版 ${ }^{[13]}$ 进行.

\section{2 结果与分析}

\section{1 形态及培养特征}

通过对 20 份青海湖水样的富集篮选、平板涂布和三次平板划线分离纯化,依据平板菌落不同生长形态 特征, 初步筛选出青海湖嗜盐微生物种质资源 35 株, 其中细菌 34 株, 真菌 1 株, 具体结果见表 1. 在菌落形 态特征上, 圆形或椭圆形占 $88.57 \%$, 颜色以白色或乳白色居多, 其中因天然色素存在于一些菌体中, 菌落呈 红色、橙红色、黄色或淡蓝色,约占 $40 \%$. 在显微结构形态上, 长杆或短杆状约占 $80 \%$, 球形或弧形约占 $14.28 \%$, 丝状约占 $5.7 \%$, 革兰氏染色阴性菌约占 $74.28 \%$. 
表 1 青海湖水体嗜盐微生物菌落形态特征

Tab. 1 The colony morphology of halophile microorganisms in Lake Qinghai

\begin{tabular}{llll}
\hline 菌株 菌落形态特征 菌落形态特征 & \\
\hline
\end{tabular}

QHL-1 规则圆形、土黄色、透明、中心突出、边缘光滑、形 态居中

QHL-2 规则圆形、乳白色、透明、隆起、边缘光滑、形态 居中

QHL-3 规则圆形、土黄色、不透明、隆起、边缘光滑、生长 迅速

QHL-4 圆形、白色、透明、隆起、边缘光滑、生长缓慢

QHL-5 圆或椭圆、白色、透明隆起、边缘光滑、形态大、生 长快速

QHL-6 圆形、淡红色、不透明隆起、边缘光滑、形态居中、 中心呈环

QHL-7 圆形、淡红色、不透明、中心隆起、边缘光滑、呈 环带

QHL-8 圆形或椭圆形、黄色、透明、边缘光滑、生长快速

QHL-9 圆形、乳白色 (中心深于边缘)、透明略隆起、边缘 不整齐

QHL-10 圆形、乳白色、不透明、隆起、边缘规则

QHL-11 圆形、乳白色、半透明、中心隆起、边缘扩散, 毛刺 呈环带

QHL-12 圆形、米黄色、边缘透明发亮、形态较大、生长快速

QHL-13 圆形、乳白色、边缘透明、形态较大、具有折射光色

QHL-14 圆形、红色、中心不透明、边缘发亮、形态居中、生 长快速

QHL-15 真菌类, 形态较大, 中心隆起、初期生长白色, 黑色 孢子

QHL-16 圆形、白色、不透明、隆起、边缘规则透亮、生长 较快

QHL-17 圆形、棕红色、不透明、隆起、边缘透亮、形态居中

QHL-18 圆形、乳白色、不透明、边缘透亮、形态居中
QHL-19 圆形淡蓝色、透明隆起、边缘光滑、形态较大、具折 射光色

QHL-20 圆形、白色、不透明、中心隆起、边缘透明光滑、形 态居中

QHL-21 规则圆形、白色、不透明、隆起、形态较小、生长 缓慢

QHL-22 规则圆形、白色、透明、隆起、形态较小

QHL-23 形态较大, 呈圆点状,白色、半透明、隆起

QHL-24 形态较小, 呈圆点状,红色、半透明、隆起

QHL-25 圆或栯圆形、乳白色、不透明、中心突出、边缘透明

QHL-26 圆形、乳白色、透明、中心凹陷、易生长粘连

QHL-27 圆形、淡蓝色、透明、形态较大、中心呈环

QHL-28 圆形、乳白色、透明、边缘规则、形态居中

QHL-29 形态极小、针点状分布、淡红色、隆起半透明、生长 缓慢

QHL-30 形态极小、针点状分布、乳白色、隆起、透明

QHL-31 形态较小、针点状分布、黄色、隆起、不透明

QHL-32 形态较小、规则、稀散分布、淡黄色、隆起、透明

QHL-33 圆形、乳黄色、边缘毛刺、形态居中、稍隆起、易生 长粘连

QHL-34 规则圆点状、白色、透明、隆起、形态较小、生长 缓慢

QHL-35＼cjkstart圆或椭圆形、无色、透明、边缘不规则、易生长粘连

\section{2 嗜盐特性与分类统计}

通过耐盐梯度试验, 确定 35 株嗜盐微生物种质资源的生长盐度范围和最适生长盐度范围 (表 2 ), 参照 嗜盐微生物分类标准 ${ }^{[14]}$ 进行初步分类, 结果表明水体中嗜盐微生物以中度嗜盐菌为主,约占 $62.85 \%$, 轻度 嗜盐菌约占 $22.85 \%$, 非嗜盐菌与耐盐菌约占 $14.28 \%$, 未分离出边界和极端嗜盐菌 (表 3 ). 依据获得的种质 资源进行统计分析, 中度嗜盐菌和轻度嗜盐菌应为青海湖嗜盐菌生长优势种群, 青海湖相对偏低的盐度环 境为中度嗜盐菌和轻度嗜盐菌的长期进化和适应性生存提供了必要条件.

\section{3 生长特性研究}

从初步分离获取的 22 株中度嗜盐微生物中, 选择生长盐度范围较为宽泛, 最适生长盐度范围较高 的典型菌株 15 株, 进行生长特性研究, 结果表明: 青海湖中度嗜盐微生物能在 $10 \sim 45^{\circ} \mathrm{C}$ 温度范围生 长, 其中一些菌株甚至能在 $5^{\circ} \mathrm{C}$ 生长, 此与青海湖地处高原地区环境有关, 水温随季节而变化 (表 4 ). 青海湖区深居大陆腹地, 属典型的大陆性中纬度高海拔寒冷半干旱气侯, 7 月份平均气温为 $12.4^{\circ} \mathrm{C}$, 极端最高温度为 $28^{\circ} \mathrm{C}, 1$ 月份平均气温为 $-12.7^{\circ} \mathrm{C}$, 极端最低气温达 $-30^{\circ} \mathrm{C}^{[15]}$. 青海湖湖水 $\mathrm{pH}$ 范围 为 $8.92 \sim 9.28^{[16]}$, 所分离的中度嗜盐微生物能在 $\mathrm{pH}$ 为 $5.5 \sim 11.0$ 的范围内生长, 且最适 $\mathrm{pH}$ 均大于 7.5 , 这与地区盐碱化环境密切相关, 具有嗜盐兼性嗜碱的特性. 因菌种属性的差异, 中度嗜盐菌对 $\mathrm{Mg}^{2+}$ 的生长需求不同, 耐受程度亦不同, 最大浓度达到 $1.6 \mathrm{~mol} / \mathrm{L}$. 在优化培养条件下, $O D_{600}$ 达到 1.20 左右的培养时间为 $8 \sim 12 \mathrm{~h}$. 
表 2 青海湖水体嗜盐微生物生长盐度和最适盐度

Tab. 2 The growth salinity range and optimum salinity of halophile microorganisms in Lake Qinghai

\begin{tabular}{ccccccccc}
\hline $\begin{array}{c}\text { 菌种 } \\
\text { 编号 }\end{array}$ & $\begin{array}{c}\text { 盐度范围 } \\
/(\mathrm{mol} / \mathrm{L})\end{array}$ & $\begin{array}{c}\text { 最适盐度 } \\
/(\mathrm{mol} / \mathrm{L})\end{array}$ & $\begin{array}{c}\text { 菌种 } \\
\text { 编号 }\end{array}$ & $\begin{array}{c}\text { 盐度范围 } \\
/(\mathrm{mol} / \mathrm{L})\end{array}$ & $\begin{array}{c}\text { 最适盐度 } \\
/(\mathrm{mol} / \mathrm{L})\end{array}$ & $\begin{array}{c}\text { 菌种 } \\
\text { 编号 }\end{array}$ & $\begin{array}{c}\text { 盐度范围 } \\
/(\mathrm{mol} / \mathrm{L})\end{array}$ & $\begin{array}{c}\text { 最适盐度 } \\
/(\mathrm{mol} / \mathrm{L})\end{array}$ \\
\hline QHL-1 & $0.04 \sim 2.74$ & 0.86 & QHL-13 & $0.04 \sim 1.11$ & 0.43 & QHL-25 & $0 \sim 2.9$ & 1.45 \\
QHL-2 & $0 \sim 1.71$ & 0.77 & QHL-14 & $0 \sim 1.71$ & 0.77 & QHL-26 & $0 \sim 2.24$ & 1.18 \\
QHL-3 & $0 \sim 1.45$ & 0.60 & QHL-15 & $0 \sim 2.74$ & 0.51 & QHL-27 & $0 \sim 1.71$ & 0.21 \\
QHL-4 & $0 \sim 1.71$ & 1.11 & QHL-16 & $0 \sim 2.74$ & 0.60 & QHL-28 & $0 \sim 1.45$ & 1.03 \\
QHL-5 & $0.04 \sim 2.99$ & 0.86 & QHL-17 & $0 \sim 1.63$ & 0.51 & QHL-29 & $0 \sim 0.86$ & 0.085 \\
QHL-6 & $0.26 \sim 1.45$ & 0.77 & QHL-18 & $0 \sim 1.63$ & 0.60 & QHL-30 & $0 \sim 1.45$ & 0.21 \\
QHL-7 & $0 \sim 1.39$ & 0.09 & QHL-19 & $0 \sim 1.71$ & 0.51 & QHL-31 & $0 \sim 1.80$ & 0.09 \\
QHL-8 & $0 \sim 2.74$ & 0.60 & QHL-20 & $0 \sim 1.71$ & 0.21 & QHL-32 & $0 \sim 0.86$ & 0.21 \\
QHL-9 & $0 \sim 1.54$ & 1.03 & QHL-21 & $0 \sim 1.06$ & 0.09 & QHL-33 & $0 \sim 1.37$ & 0.43 \\
QHL-10 & $0 \sim 1.37$ & 0.51 & QHL-22 & $0 \sim 1.28$ & 0.31 & QHL-34 & $0 \sim 0.68$ & 0.43 \\
QHL-11 & $0 \sim 1.71$ & 1.11 & QHL-23 & $0.09 \sim 1.63$ & 1.03 & QHL-35 & $0 \sim 2.74$ & 0.77 \\
QHL-12 & $0 \sim 1.37$ & 0.17 & QHL-24 & $0 \sim 2.1$ & 1.03 & & & \\
\hline
\end{tabular}

表 3 青海湖水体嗜盐微生物分布情况

Tab. 3 The species distribution of halophile microorganisms in Lake Qinghai

\begin{tabular}{|c|c|c|c|}
\hline 类型 & 生长盐度 $/(\mathrm{mol} / \mathrm{L})$ & 最适盐度/( mol/L) & 实验菌种编号 \\
\hline 非嗜盐微生物 & $0 \sim 1.0$ & $<0.2$ & $29^{\#}$ \\
\hline 轻度嗜盐微生物 & $0.2 \sim 2.0$ & $0.2 \sim 0.5$ & $13^{\#}, 20^{\#}, 22^{\#}, 27^{\#}, 30^{\#}, 32^{\#} \sim 34^{\#}$ \\
\hline 中度喏盐微生物 & $0.4 \sim 3.5$ & $0.5 \sim 2.0$ & $1^{\#} \sim 6^{\#} 、 8^{\#} \sim 11^{\#} 、 14^{\#} \sim 19^{\#} 、 23^{\#} \sim 26^{\#} 、 28^{\#} 、 35^{\#}$ \\
\hline 边界极端嗜盐微生物 & $1.4 \sim 3.5$ & $2.0 \sim 3.0$ & \\
\hline 极端嗜盐微生物 & $2.0 \sim 5.2$ & $>3.0$ & \\
\hline 耐盐微生物 & $0 \sim 1.0$ & $<0.2$ & $7^{\#}, 12^{\#}, 21^{\#}, 31^{\#}$ \\
\hline 万能耐盐微生物 & $0 \sim 3.0$ & $0.2 \sim 0.5$ & \\
\hline
\end{tabular}

表 4 青海湖水体嗜盐微生物生长特性

Tab. 4 The growth characteristics of halophile microorganisms in Lake Qinghai

\begin{tabular}{cccccccc}
\hline $\begin{array}{c}\text { 菌种 } \\
\text { 编号 }\end{array}$ & $\begin{array}{c}\text { 温度范围 } \\
/{ }^{\circ} \mathrm{C}\end{array}$ & $\begin{array}{c}\text { 最适温度 } \\
/{ }^{\circ} \mathrm{C}\end{array}$ & $\begin{array}{c}\mathrm{pH} \\
\text { 范围 }\end{array}$ & $\begin{array}{c}\text { 最适 } \\
\mathrm{pH}\end{array}$ & $\begin{array}{c}\mathrm{Mg}^{2} \text { 浓度 } \\
/(\mathrm{mol} / \mathrm{L})\end{array}$ & $\begin{array}{c}\text { 最适 } \mathrm{Mg}^{2+} \text { 浓度 } \\
/(\mathrm{mol} / \mathrm{L})\end{array}$ & $\begin{array}{c}\text { 培养时间 } \\
/ \mathrm{h}\end{array}$ \\
\hline QHL-1 & $10 \sim 45$ & 37 & $4.5 \sim 10.0$ & 8.5 & $0 \sim 1.60$ & $0.2 \sim 0.8$ & 8 \\
QHL-2 & $10 \sim 45$ & $35 \sim 37$ & $5.0 \sim 10.5$ & 7.5 & $0 \sim 1.60$ & $0.1 \sim 0.6$ & 8 \\
QHL-3 & $15 \sim 50$ & 37 & $5.0 \sim 11.0$ & 9.0 & $0.01 \sim 0.40$ & 0.02 & 8 \\
QHL-4 & $25 \sim 50$ & 30 & $5.0 \sim 11.0$ & 9.0 & $0.01 \sim 1.00$ & $0.1 \sim 0.2$ & 16 \\
QHL-5 & $5 \sim 45$ & $35 \sim 37$ & $6.0 \sim 11.5$ & $8.5 \sim 9.5$ & $0.01 \sim 1.25$ & $0.08 \sim 0.40$ & 8 \\
QHL-8 & $15 \sim 50$ & 35 & $5.5 \sim 10.5$ & 8.0 & $0 \sim 1.20$ & $<0.06$ & 8 \\
QHL-9 & $15 \sim 45$ & $35 \sim 37$ & $5.5 \sim 11.0$ & 10.0 & $0.01 \sim 0.40$ & 0.02 & 12 \\
QHL-11 & $10 \sim 45$ & $35 \sim 37$ & $5.5 \sim 11.0$ & 10.0 & $0.01 \sim 0.40$ & 0.04 & 12 \\
QHL-16 & $15 \sim 45$ & 30 & $5 \sim 11.0$ & 10.0 & $0 \sim 1.60$ & 1.0 & 8 \\
QHL-19 & $5 \sim 50$ & 35 & $6.0 \sim 10.5$ & $9.0 \sim 10.0$ & $0 \sim 1.60$ & 0.03 & 12 \\
QHL-23 & $5 \sim 50$ & 35 & $6.0 \sim 10.5$ & 9.0 & $0.1 \sim 1.80$ & 1.2 & 12 \\
QHL-24 & $10 \sim 45$ & 35 & $6.0 \sim 10.5$ & 7.5 & $0 \sim 1.80$ & $0.2 \sim 0.8$ & 12 \\
QHL-26 & $5 \sim 45$ & 37 & $6.0 \sim 11.0$ & $7.0 \sim 9.0$ & $0 \sim 1.60$ & 0.1 & 12 \\
QHL-28 & $15 \sim 45$ & 37 & $5.5 \sim 10.5$ & 7.5 & $0.10 \sim 1.40$ & $0.04 \sim 0.08$ & 12 \\
QHL-35 & $15 \sim 45$ & 37 & $5.5 \sim 11.0$ & 8.5 & $0 \sim 1.60$ & 1.0 & 12 \\
\hline
\end{tabular}




\section{4 碳氮源利用}

对上述的 15 株典型中度嗜盐菌株进行碳氮源利用实验,结果表明大多数青海湖中度嗜盐菌能以果糖、 蔗糖、葡萄糖、麦芽糖、乳糖、半乳糖、木糖、鼠李糖、棉子糖、海藻糖和纤维二糖作为碳源, 良好生长; 其它碳 源利用因菌株差异而不同. 在氮源利用方面, 大多数菌株能良好利用酵母抽提物、蛋白胨、硫酸铵、硝酸铵、 氯化铵、尿素、硝酸钾、硝酸钠和硝酸钾进行生长; 不能良好利用亚硝酸钠生长 (表 5 ).

表 5 青海湖中度嗜盐微生物碳氮源利用情况

Tab. 5 The utilization of carbon and nitrogen sources by moderate halophile microorganisms in Lake Qinghai

\begin{tabular}{|c|c|c|c|c|c|c|c|c|c|c|c|c|c|c|c|}
\hline \multirow{2}{*}{ 碳氮源 } & \multicolumn{15}{|c|}{ 菌株编号 } \\
\hline & 1 & 2 & 3 & 4 & 5 & 8 & 9 & 11 & 16 & 19 & 23 & 24 & 26 & 28 & 35 \\
\hline
\end{tabular}

\section{L-Glycine}

L-Glutamate

L-Isoleucine

DL-Threonine

DL-Tryptophan

L-Valine

L-Lysine

L-Phenylalanine

L-Alanine

D-Fructose

Sucrose

D-Glucose

Maltose

Melibiose

Melezitose

D-Galactose

Lactose

Sorbitol

Xylitol

D-Xylose

D-Mannose

Mannitol

Rhamnose

Raffinose

Trehalose

Ribose

L-Arabinose

Cellobiose

Soluble starch

Inositol

Creatine

Ethanol

Acetone

Glycerin

Yeast extract

Tryptone

Urea

Ammonium salt ${ }^{1)}$

$\mathrm{NH}_{4} \mathrm{H}_{2} \mathrm{PO}_{4}$

Nitrate $^{2)}$

Sodium nitrite

1) 表示硝酸铵、硫酸铵与氯化铵;2) 表示硝酸钠、硝酸钾与硝酸钻; + 表示能利用生长; - 表示不能利用生长. 


\section{3 讨论与结论}

从 20 份水样中笁选分离出 35 株嗜盐微生物, 其中以中度嗜盐菌为主, 约占 $62.85 \%$, 轻度嗜盐菌约占 $22.85 \%$, 非嗜盐菌与而盐菌约占 $14.28 \%$, 未分离出边界和极端嗜盐菌, 此与湖水盐度环境密切相关. 青海 湖水体盐度为 $13.24 \sim 14.05 \mathrm{~g} / \mathrm{L}^{[17]}, \mathrm{Na}^{+}$浓度变化范围是 $2.56 \sim 7.08 \mathrm{~g} / \mathrm{L}$, 平均值为 $4.92 \mathrm{~g} / \mathrm{L}^{[18]} ; \mathrm{Cl}^{-}$浓度 变化范围是 $3.57 \sim 10.29 \mathrm{~g} / \mathrm{L}$, 平均值为 $7.23 \mathrm{~g} / \mathrm{L}^{[18]}$. 国内学者从南海、黄海、青岛盐田等区域, 曾分离出边 界和极端嗜盐菌, 通过水体盐度比较可知 ${ }^{[19]}$ : 青海湖水体盐度相对低于南中国海 $(33.2 \mathrm{~g} / \mathrm{L})$ 和黄海 $(33.1 \mathrm{~g} / \mathrm{L})$, 此与青海湖湖水源补给密切相关, 其来源主要是河水, 其次是湖底的泉水和降水. 从青海湖分 离篮选的种质资源分析表明, 中度嗜盐菌和轻度嗜盐菌应为生长优势种群, 因青海湖相对偏低的盐度环境, 为中度嗜盐菌和轻度嗜盐菌的长期进化和适应性生存提供了必要条件.

青海湖中度嗜盐菌能在 $10 \sim 45^{\circ} \mathrm{C}$ 生长, 其中一些菌株甚至能在 $5^{\circ} \mathrm{C}$ 生长, 与青海湖地处高原地区环境有 关, 但其生长速度相对缓慢, 大部分菌株最适生长温度在 $30 \sim 37^{\circ} \mathrm{C}$ 之间. 青海湖湖域温度具有明显的地域特 征 ${ }^{[20]}$ : 年最高气温为 $19.8 \sim 35.7^{\circ} \mathrm{C}$, 年最低气温为 $-36.9 \sim 15.0^{\circ} \mathrm{C}$, 年平均气温为 $-4.2 \sim 7.1^{\circ} \mathrm{C}$, 极端最低 气温 $-33.4 \sim-31^{\circ} \mathrm{C}$. 而且高原地区昼夜温差变化显著, 青海湖嗜盐菌对温度适应能力较强, 生长温度范围 较宽. 所分离的中度嗜盐菌能在 $\mathrm{pH}$ 为 $5.5 \sim 11$ 的范围内生长, 且最适 $\mathrm{pH}$ 均大于 7.5 , 具有嗜盐兼性嗜碱的 特性. 青海湖湖水的 $\mathrm{pH}$ 值范围为 $8.90 \sim 9.09$, 均值为 $9.05^{[16]}$; 主要人湖河流 $\mathrm{pH}$ 范围为 $8.41 \sim 9.01$, 均值 为 $8.56^{[16]}$, 表明青海湖流域水质呈碱性, 可能与青海湖地区大气降水和表层土壤都呈碱性有关, 因此影响 嗜盐菌对碱性环境的而受. 水体中阳离子以 $\mathrm{Na}^{+} 、 \mathrm{~K}^{+} 、 \mathrm{Mg}^{2+}$ 为主, $\mathrm{Ca}^{2+}$ 含量偏少, 但 $\mathrm{Mg}^{2+} / \mathrm{Ca}^{2+}$ 比值较大, 此 与青海湖大量的方解石和文石沉积有关 ${ }^{[21]}$. 阴离子主要有 $\mathrm{Cl}^{-} 、 \mathrm{SO}_{4}^{2-} 、 \mathrm{NO}_{3}^{-}$和 $\mathrm{HCO}_{3}^{-}$, 以 $\mathrm{Cl}^{-}$为主, 属典型的 大陆内陆水体特征 ${ }^{[16]}$. 因此, 菌种种属的差异导致中度嗜盐菌对 $\mathrm{Mg}^{2+}$ 的生长需求不同, 耐受程度亦不同, 最 大浓度达到 $1.6 \mathrm{~mol} / \mathrm{L}$, 其中一些菌株依赖 $\mathrm{Mg}^{2}$ 的存在而生长代谢, 即使是极低浓度 $\mathrm{Mg}^{2+}$. 大多数青海湖中 度嗜盐菌能以果糖、蔗糖、葡萄糖、麦芽糖、乳糖、半乳糖、木糖、鼠李糖、棉子糖、海藻糖和纤维二糖作为碳 源, 生长良好. 在氮源利用方面, 大多数菌株能良好利用有机氮源、铵盐、硝酸盐进行生长, 但大多数菌株不 能利用亚硝酸盐. 近年来, 青海湖中硝酸盐含量逐年呈上升趋势, 为微生物生长提供良好的氮源条件; 青海 湖流域河流 DOC 含量为 $6.35 \sim 12.65 \mathrm{mg} / \mathrm{L}$, 平均浓度为 $10.5 \mathrm{mg} / \mathrm{L}^{[18]}$, 湖水 DOC 含量为 $334.26 \sim$ $518.82 \mathrm{mg} / \mathrm{L}$, 平均浓度为 $453.7 \mathrm{mg} / \mathrm{L}^{[18]}$, 为湖边域微生物的生长和繁殖提供了充足的营养基质.

青藏高原地区特殊的气候条件和自然地理条件造就了青海湖典型的高原盐湖沉积环境和湖泊相对封 闭水体, 且沉积物和湖域周边牧区丰富的有机物质为微生物的生长代谢提供了充足的养料. 通过获得的青 海湖嗜盐菌种质资源, 初步研究其生长特性, 以此了解青海湖嗜盐微生物的多样性, 为后续青海湖微生物生 态学、种群系统发育和进化定位分析等研究工作奠定坚实的基础.

\section{4 参考文献}

[ 1 ] 李迪强,蒋志利,王祖望. 青海湖地区生物多样性的空间特征与 GAP 分析. 自然资源学报,1999,14(1):47-53.

[2] 山发寿,杜乃秋,孔昭宸. 青海湖盆地 35 万年来的植被演化及环境变迁. 湖泊科学, 1993,5(1):9-17.

[ 3 ] 赵百锁,杨礼富,宋 蕾等. 中度嗜盐菌在生物技术中的应用. 微生物学通报, 2007,34(2):359-362.

[ 4 ] 张小华,陈皓文.海洋原核生物名称. 北京:科学出版社,2009:1-2.

[ 5 ] George MG, Julia AB, Timothy GL. Taxonomic outline of the prokaryotes Bergey's manual of systematic bacteriology: 2nd edition. New York: Berlin Heidelberg, 2004: 19-22.

[6] 迪丽拜尔・托乎提. 新疆罗布泊周边地区极端环境嗜盐菌的研究.生物技术,2009,19(5):16-20.

[ 7 ] 陈志亮, 陈荣忠. 南极深海底泥中度嗜盐菌盐单胞菌属 Nj223ectC 基因的克隆表达及 ectoine 合成酶性质分析. 微生 物学报, $2007, \mathbf{4 7}(2): 363-365$.

[8] 崔春晓, 戴美学, 夏志洁. 盐地碱蓬内生中度嗜盐菌的分离与系统发育多样性分析. 微生物学通报, 2010,37(2): 204-210.

[ 9 ] 周旭华,吴 敏. 舟山地区 26 株嗜盐菌的系统发育分析. 现代农业科学,2009,16(4):44-45.

[10］徐晓红,吴 敏. 嗜盐古生菌 AJ6 的分离及系统发育分析. 浙江大学学报,2005,32(1):83-87. 
[11］张晓梅.一株产脂肪酶嗜盐菌的鉴定及耐盐机理. 应用与环境生物学报,2010,16(1):100-103.

[12] 东秀珠,蔡妙英. 常用细菌系统鉴定手册. 北京:科学出版社,2001:364-370.

[13] 布坎南 RE,吉本斯 NE. 伯杰氏细菌鉴定手册:第 8 版. 北京:科学出版社, 1984:353-357.

[14] 曹卫军,沈 萍,李朝阳. 嗜极微生物. 武汉: 武汉大学出版社, 2004:1-19.

[15] 淮虎银, 周立华. 青海湖湖盆南岸植物群落的生态优势度与海拔梯度. 西北植物学报, 1995, 15 (3):240-243.

[16] 侯昭华,徐 海,安芷生. 青海湖流域水化学主离子特征及控制因素初探. 地球与环境,2009,37(1):11-19.

[17］张恩楼,沈 吉,王苏民. 近 $0.9 \mathrm{ka}$ 来青海湖湖水盐度的定量恢复. 科学通报, 2004,49(7):697-701.

[18] 张 琨,蓝江湖,沈振兴等. 青海湖流域水化学分析及水质初步评价. 地球环境学报,2010,(3):162-168.

[19] 妥进才, 陈 骏,姚素平等. 青海湖: 研究地质微生物的天然实验室. 高校地质学报,2005,11(2):187-193.

[20］孙永亮,李小雁,汤 佳. 青海湖流域气候变化及其水文效应. 资源科学,2008,30(3):653-655.

[21] 刘兴起,沈吉,王苏民等. $16 \mathrm{ka}$ 以来青海湖湖相自生碳酸盐沉积记录的古气候. 高校地质学报, 2003,9(1): $38-46$. 